\title{
Autonomy and Monitoring ${ }^{\Omega}$
}

\author{
Marco A. Barrenechea-Méndez, PhD. \\ Universitat Pompeu Fabra
}

Edifici Roger de Llúria (campus de la Ciutadella) Ramon Trias Fargas, 25-27 08005

Barcelona

E-mail: Marco.barrenechea@upf.edu

Telephone number: 0034699617540

Pedro Ortín-Ángel, PhD.

Universitat Autònoma de Barcelona

Fac. CC. Econòmiques i Empresarials - Edifici B Universitat Autònoma de Barcelona 08193 Bellaterra (Cerdanyola del Vallès)

E-mail: Pere.ortin@uab.es

Telephone number: 0034935811209

Eduardo C. Rodes, PhD.

Universitat Autònoma de Barcelona

Fac. CC. Econòmiques i Empresarials - Edifici B Universitat Autònoma de Barcelona

08193 Bellaterra (Cerdanyola del Vallès)

E-mail: Eduardo.rodes@uab.es

Telephone number: 0034935811209

\footnotetext{
${ }^{\Omega}$ The authors acknowledge financial support from the Spanish Ministry of Education, ECO 2013-48496C4-4-R. We are grateful for the helpful comments provided by two anonymous referees and by Matthew Ellman, Tor Eriksson, Vicente Salas-Fumás and participants at various conferences and workshops.
} 


\begin{abstract}
This paper provides a theoretical and empirical analysis of an under-explored consequence of granting autonomy to workers: monitoring. In the principal-agent model that we develop, granting autonomy allows workers to carry out innovative tasks in the workplace. Given that innovative tasks are more difficult to monitor, the model predicts a positive relationship between autonomy and monitoring. Relying on information about blue-collar workers coming from a dataset of Spanish industrial plants, we provide strong support for this prediction.
\end{abstract}

Keywords: Autonomy, monitoring, wages and organisation design

JEL Classification: M52, J33 


\section{Introduction}

Aghion and Tirole (1997) set out the theoretical foundations of a growing body of economic literature on authority in organizations. A worker's real authority, or autonomy, is understood as being the capability of the worker to decide on the task to be performed. The bulk of this literature (see Bolton and Dewatripont 2012 for a summary) focuses on the effects of autonomy on workers' efforts to collect information in order to be able to select the task to be performed. The present paper contributes to this literature by stressing another effect of granting autonomy: its consequences on the effort that workers exert on the execution of the task that is finally implemented. More specifically, we are interested in the relationship between autonomy and two mechanisms of the job design needed to elicit this productive effort: monitoring and compensation. When we talk of monitoring, we refer to efforts made by the firm (e.g. supervisors' performance appraisal) to gather information about the way workers carry out productive tasks (inputs and/or outputs) ${ }^{1}$.

Several case studies, such as those by Nordstrom or Whole Foods Market or the bulk of those presented by Kaplan and Norton (2001), show a clear interaction between autonomy, monitoring and compensation. Nordstrom is a very successful firm in the apparel industry that gives sales clerks a lot of discretion in the way they carry out their work. Sarcastically, they call "the employee handbook" to a single five-by-eight-inch card, where the only rule states: “...use your good judgment in all situations. There will be no additional rules" (Collins and Porras 1994, p. 117). This sound philosophy is reinforced by the point of view expressed by the CEO Jim Nordstrom: "You can do anything you need to at Nordstrom, just so long as you live up to our basic values or

\footnotetext{
${ }^{1}$ It has been argued that autonomy and monitoring are antonymous terms (Neal 1993), related to the workers' degree of empowerment to make a certain decision. Note that we use the term autonomy to refer to the degree of empowerment for the selection of the task to be performed, while we use the term monitoring to refer to the degree of empowerment for the execution of the task.
} 
standards" (Collins and Porras 1994, p. 138). At the same time, they use sales per hour for monitoring purposes, calling it $^{2}$ "the heart of Nordstrom's distinctive management strategy". This information influences pay, the availability of better hours and days and career opportunities.

In the supermarket chain Whole Foods Market, "Small, empowered work groups are responsible for all key operating decisions, including pricing, ordering, staffing, and instore promotion. While associates are highly empowered, they are also highly accountable. Every four weeks, Whole Foods Market calculates the profit per labor hour for every team in every store. Teams that exceed a certain threshold get a bonus in their next paycheck..." (Hamel and Breen 2009, p.5)

Thus, it is not surprising that the managerial and accounting literature suggests that the innovations resulting from workers' empowerment will imply changes in the monitoring and compensation systems. The following statement underscores this idea.

"(Employees) may innovate and find new and unexpected ways to achieve high-level strategic objectives or identify variations in the strategy that open up new growth opportunities."(p.315)"Companies have been attempting to implement change for decades. Why do we advocate that change initiatives now be accompanied by a change in the measurement system to the Balanced Scorecard? Adapting the organization's measurement system to the change agenda is critical for success.(p.343) "The final linkage from high-level strategy to day-today actions occurs when companies link individuals' incentive and reward programs to the Balanced Scorecard" (p.253).

R.S. Kaplan and D.P. Norton, 2001, The Strategy-Focused Organization

This anecdotal literature does not address the questions of why and how such decisions are interrelated. The way in which these variables of the job design interact is not straightforward. It might be plausible to consider different combinations. For

\footnotetext{
${ }^{2}$ See p. 7 of the case study: Nordstrom: Dissension in the Ranks (A), Harvard Business School (9-191002), 1999.
} 
example, are monitoring and compensation going to be higher (or lower) in contexts in which workers are empowered? Are firms going to provide less autonomy when monitoring costs and compensation levels are higher (lower)?

This paper sets up a principal-agent model that provides insights into these questions. The firm (principal) decides whether to grant workers (agents) rights that allow then to make decisions on selecting the task needed to perform their job, and establish the monitoring and compensation levels that are contingent on this decision. The worker decides whether or not to implement a new task when this is possible, and the effort exerted in performing such a task.

The main contribution of the model is to emphasise the effects of autonomy on the monitoring and compensation levels. Our explanation is based on the assumption that the firm has a comparative advantage in monitoring a customary task vis-à-vis an innovative task, i.e. the same quality of information can be obtained in the first case at a lower monitoring cost. The anecdotal literature cited above suggests that the nature of the task, whether customary or innovative, may determine different monitoring and compensation arrangements. Examples of monitoring arrangements are the ones suggested by the managerial accounting literature and associated with the implementation of monitoring systems, such as budgeting control, activity-based costs or the balanced scorecard. Some monitoring effort will entail sunk costs, for example training supervisors to understand the information to be gathered and the procedures established for gathering it. The comparative advantage in monitoring the customary task may come, for example, from not incurring such sunk costs again.

The remaining assumptions are in common use in the literature on authority in organizations (Bolton and Dewatripont 2012) or the provision of incentives in firms (for a summary see Prendergast 1999). Authority is usually linked to the assumption that both 
firms and workers have private benefits related to different tasks. We depart from most of this literature by assuming that only firms obtain positive private benefits when an innovative task is implemented. Following Prendergast (2002), we assume that workers acquire private information on the best way to carry out the job when a firm places them in their jobs. This information cannot be communicated to management without cost. Therefore only the workers can decide if an innovation is introduced or not.

In addition to the differences in monitoring tasks, our model differs from Prendergast (2002) in that the firms' benefits are private, and workers do not obtain private benefits from selecting a given task. These last assumptions are made for the sake of expositional simplicity, not based on their realism. The assumptions avoid any other conflict of interests other than the one that the paper wishes to highlight. Autonomy allows the worker to introduce innovations whenever it is possible. When the increase in monitoring costs and wages does not compensate for the associated private benefits, the firm centralises decisions.

The model also relies on several assumptions made in the literature on the provision of incentives in firms for linking monitoring and compensation. Specifically, models usually assume that in order to elicit effort from workers, firms must link their compensation to the (imperfect) information provided by the monitoring system about the effort exerted. We have designed the optimal monitoring system relying on Demougin and Fluet $(1998,2001)$. These authors show that in order to obtain a certain level of worker's effort in a context of moral hazard, risk neutrality and limited liability, the features of the monitoring system can be summarised into just one parameter: the quality of information. We have borrowed this result in order to make our model more manageable. 
The main prediction of the model is that monitoring will be higher in those firms that provide autonomy. Typically, the information needed to test this hypothesis, i.e. the measures for monitoring and autonomy in the same dataset, is not available ${ }^{3}$. A distinctive characteristic of our data is that it specifically measures those variables. We rely on a database of Spanish industrial plants providing information about work organization practices for blue-collar workers. The data strongly supports the relationship predicted by the model. The model also suggests that in firms that pay above the market, higher levels of monitoring imply less rent to their workers. This prediction also receives strong support.

The remainder of the paper is organized as follows: In Section 2, we develop the model and state its empirical implications. In Section 3, we present the empirical strategy, the data and the results of the estimations. In Section 4, we conclude with the theoretical and empirical implications of the paper.

\section{The model}

\subsection{Model structure and main assumptions}

We use a principal-agent model with moral hazard, which considers a risk neutral firm and a risk neutral worker protected by limited liability. In what follows, our efforts will focus on setting out the job design within the contingent contract that the firm offers to the worker at the beginning of the contractual relationship. The model assumes that the optimal contract has to take into account the interactions between autonomy, monitoring

\footnotetext{
${ }^{3}$ For instance, we have not found such information in surveys such as the European Company Survey 2008 of the European Foundation, the $5^{\text {th }}$ European Survey on Working Conditions (2010) or the Workplace Employment Relations Study 2011
} 
and compensation. Figure 1 shows the states of nature realized and the different decisions made from the offering of the contract until its execution.

--Figure 1--

Stage 0. For the sake of simplicity, we summarize the possible ways in which a job can be performed, reducing them to just two tasks, the customary task, denoted by $d=0$, and the innovative task, denoted by $d=1$. In this stage, it is common knowledge that there is a certain positive probability, $\lambda>0$, that an innovative task will be feasible when the worker is appointed to the workplace. Given its experience, the firm could have an insight into the potential a given worker might have to introduce an innovation. In addition, the worker could have a good idea of their abilities and therefore an insight into their potential to introduce an innovation. We assume that the introduction of an innovation $(d=1)$ implies a reduction in production costs ${ }^{4}$ of $B$. This cost reduction is observable by the worker and the firm but not by third parties, consequently, we assume that it is non-contractible.

Stage 1.The firm offers a contract after $\lambda$ and $B$ are known. Following Demougin and Fluet $(1998,2001)$, we assume that the firm is risk neutral and its problem is to design a contract that minimizes the expected costs for ensuring that the worker executes a task with a certain level of effort $\hat{e}$. The contract is designed in order to be accepted by the agent. The firm offers a contingent contract with different levels of autonomy, monitoring and wages. We assume that the worker is risk neutral but protected by limited liability ${ }^{5}$. The maximum fine that she can receive is $F \geq 0$. This can also be interpreted in terms of

\footnotetext{
${ }^{4}$ In a seminal book, Landau and Rosemberg (1986) offer a series of contexts in which the introduction of innovations result in cost reduction.

${ }^{5}$ Limited liability is a common justification for the use of efficiency wages or the existence of rents as incentive devices (see, for example the extensive literature presented by Saint-Paul 1996).
} 
the agent's ability to post a bond as it is done in the agency model (Holmström 1979). Additionally, the reservation utility for the employee is zero.

Hence, the worker's expected utility is defined as the expected wage $E(w)$ minus the cost of the effort to execute the task, represented by function $C(e)$, which is defined $\forall e \in$ $[0, \bar{e}]$, so the domain is a closed interval of efforts with the lowest value of 0 and the highest value of $\bar{e}$, where $\hat{e}<\bar{e}$. The cost of effort function has the usual regular properties, $C(0)=0, C^{\prime}(e)>0, C^{\prime \prime}(e)>0, C(\bar{e})=\infty$ and $C^{\prime}(0)=0$. We restrict our analysis to bonus-based compensation contracts, where only two (high and low) possible wages will be considered. Under the assumptions made, Kim (1997) shows that bonusbased contracts can reproduce all the first-best possible solutions obtained with other contractual forms, for example linear incentive contracts (Holmstrom 1979). Finally, the worker can always leave the firm at any of the following stages.

Stage 2: If the worker accepts the contract, she is placed in the job and observes whether the innovative task can be introduced. As commented before, the existence of a positive probability that the worker may implement an innovation is common knowledge, nevertheless, in this stage this state of nature is performed and observed exclusively by the worker. The availability of an innovation once the worker has taken up the job is private information. With this information, the worker decides whether to innovate $(d=1)$ or not $(d=0)$. When the innovative task is not available, there is no choice, $(d=0)$. The introduction of an innovative task is observable and contractible.

There is a certain amount of literature assuming non-verifiability of innovations (see for example Aghion and Tirole 1997). This is not a critical point in our model. The results would be maintained if innovations were non-verifiable but produced changes in the 
monitoring systems that can be observed. The critical point in our model is that changes in the monitoring systems are verifiable and contractible.

The worker's private information is about the actual feasibility of the innovation. Therefore the contract - which is offered in Stage 1- cannot stipulate something like "if an innovation is feasible it must be adopted". However, the contract can forbid innovations ${ }^{6}$, for example by dismissing the worker if an innovation is introduced. In that case, the worker will not receive any compensation and the firm will not incur monitoring costs. Since it is never in the interest of the worker to introduce an innovation when it is forbidden, this case does not deserve further attention. We therefore consider two situations: centralization with no innovations, and autonomy where innovations can be introduced. Whether the firm provides autonomy $(a=1)$ or centralizes $(a=0)$ is something that has to be specified in the contract. The decision about the provision of autonomy determines a set of monitoring/compensation combinations from among which the worker can select.

Note that instead of granting decision rights to the worker, we could model this interaction as a game of communication (Dessein 2002). When the worker observes the state of nature in Stage 2, "if an innovation is feasible" she sends a message recommending the innovative task, and in a truth-telling equilibrium, the firm orders the worker to undertake the recommended task. These two scenarios are plausible. We may assume costly communication, errors and credibility/commitment issues to favour our interpretation, using autonomy to implement the right task instead of the truthful revelation game.

Stage 3 . The principal invests in monitoring the task with intensity $m$. Firms can invest in monitoring mechanisms (e.g. absenteeism control systems or productivity

\footnotetext{
${ }^{6}$ Beside benefits, innovations also imply costs.
} 
measurements) to collect public and contractible information about the effort exerted by the worker in performing the task. In the case of bonus-based contracts, Demougin and Fluet (1998) show that it is optimal for the firm to summarize all the information available about the worker's performance (input, output or both) in a binary statistic $I=\{H, L\}$.

This binary information system is imperfectly correlated to the effort level, so there is a positive probability of obtaining signal $H$ for a certain level of effort $e$, monitoring intensity $m$ and the task selected $d$, which is represented by the probability function ${ }^{7}$ $P(H / e, m, d)$. Let us assume that the probability function is twice-continuously differentiable with respect to $e, P^{\prime}>0$, so $H$ can be interpreted as favourable information about the worker's effort, and $P^{\prime \prime}<0$.

Demougin and Fluet $(1998,2001)$ show that, for higher values of $=\frac{\hat{e} P^{\prime}(H / \hat{e}, m, d)}{P(H / \hat{e}, m, d)}$, it is possible to implement the level of effort $\hat{e}$ with lower (or at least the same) expected wages. Therefore, for the firm's purposes, the features of a monitoring system for a concrete task can be summarized by $\theta$, which is interpreted as a measurement of the quality (or precision) of the information provided by the monitoring system $(\theta \in[0,1])$.

We depart from Demougin and Fluet by assuming that the quality of the information about the worker's performance will depend on the introduction of innovations $(d)$ and on the monitoring intensity $(m)$ in the following way: $\theta(d) \equiv \gamma(1-d)+m$. In other words, given the level of effort $\hat{e}$, the probability of obtaining signal $H$ only depends on the quality of the information $P(H / \theta(d))$.

\footnotetext{
${ }^{7}$ One function with all the properties described below is $P(H / e, m, d)=e^{\gamma(1-d)+m}=e^{\theta}$, defined $\forall e \in$ $[0, \bar{e}=1]$.
} 
We assume that $\theta(d)$ is public information. The parameter $\gamma$ is positive and reflects the cost advantage for the firm of monitoring the customary task vis-à-vis the innovative task. The additive functional form of $\theta$ implies that the informational advantage $\gamma$ is independent of the level of monitoring intensity. Another assumption is made simply to simplify and eliminate the trivial solution that there is no need to invest in monitoring the customary task: the informational advantage of the customary task $(d=0)$ to elicit effort $\hat{e}$ is positive but sufficiently small: $0<\gamma<\frac{\hat{e} C^{\prime}(\hat{e})}{C(\hat{e})+F}$.

Let us define $M$ as the minimum level of investment needed to obtain monitoring intensity $m$. Both variables $m$ and $M$ are contractible and relate to each other according to the following function: $M=M(m)$. The function $M($.$) satisfies the usual properties,$ $M(0)=0$, is twice differentiable and continuously increasing in $m, M^{\prime}()>0,. M^{\prime \prime}()>$. and $M(1-\gamma) \rightarrow \infty$

Stage 4. After the task is chosen (together with the associated monitoring intensity), the worker exerts productive effort $e$ in performing such a task. As in standard agency models (Holmström 1979, Shavel 1979), there is asymmetric information about the level of this variable. Thus, in order to elicit the optimal level of effort, the compensation of the worker will be based on statistic $I=\{H, L\}$, where $w_{H}$ is the wage paid when a high level of performance has been observed and $w_{L}$ the wage paid when a low level of performance has been observed.

\subsection{The firm's cost minimization problem}

In this section we set out the firm's problem formally. The firm has to design the contract taking into account the fact that the worker has discretion in selecting the job 
task (verifiable and contractible) and the level of unverifiable effort. The first decision to be made is about the provision of autonomy. The level of monitoring and wages will depend on the fact that an innovation has been introduced $(d=1)$ or not $(d=0)$. This fact is reflected by the following notation: $m(d), w_{H}(d)$ and $w_{L}(d)$.

We then define the expected costs $(T C(d))$ of inducing a level of effort $\hat{e}$ of a certain task $(d)$ as the sum of the expected wages and monitoring costs:

$$
T C(d) \equiv E(w(d))+M(m(d))=P(H / \theta(d))\left(w_{H}(d)-w_{L}(d)\right)+w_{L}(d)+M(m(d))
$$

The firm solves the minimization of the cost function $O$ :

$$
\underset{a, m(d), w_{H}(d), w_{L}(d)}{\operatorname{Min}} O=a(\lambda(T C(1)-B)+(1-\lambda) T C(0))+(1-a) T C(0)
$$

s.t.

$$
\begin{aligned}
& \hat{e}=\arg \min (E(w(d))-C(e)) \quad \forall d=0,1 \\
& a[\lambda E[w(1)]+(1-\lambda) E[w(0)]+(1-a) E[w(0)]-C(\hat{e}) \geq 0 \quad \forall a=0,1 \\
& E[w(d)]-C(\hat{e}) \geq 0, \quad \forall d=0,1 \\
& w_{H}(d)+F \geq 0 \text { and } w_{L}(d)+F \geq 0 \quad \forall d=0,1 \\
& E(w(1)) \geq E(w(0))
\end{aligned}
$$

Restrictions (1) and (2) are the standard incentive compatibility and participation constraints. Restriction (3) is the interim participation constraint which guarantees that it is in the best interest of the worker to continue in the firm after the private information is revealed but before exerting effort. Restriction (4) is the limited liability constraint. 
Restriction (5) guarantees that it is in the best interest of the worker to introduce an innovation whenever possible. Remember also that $\theta(d) \equiv \gamma(1-d)+m$.

\subsection{Solution of the model}

The objective function of the firm can be rewritten as:

$$
O=a \lambda(T C(1)-T C(0)-B)+T C(0)=a \lambda(\Delta-B)+T C(0)
$$

Where $\Delta=T C(1)-T C(0)$ is the firm's cost difference between introducing or not introducing an innovation. Note that whenever $B-\Delta>0$, autonomy will be provided $(a=1$ minimizes the objective function). Whatever the decision of the worker regarding the introduction of innovations, $d=0$ or $d=1$, the minimization of the objective function implies minimizing the cost function $T C(d)$ subject to Restrictions 1 to 4 . Next, a proposition summarises the results, and Appendix 1 provides the proofs.

Proposition 1: An optimal contract to implement a level of effort $\hat{e}$ is determined by the following conditions:

a) The optimal information level about performance is:

$$
\begin{aligned}
& \theta^{*}(d)=\operatorname{Min}\left\{\theta_{R}(d), \theta_{N R}\right\} \quad, \text { where } \theta_{R}(d) \in \arg \min \left\{\frac{\hat{e} C^{\prime}(\hat{e})}{\theta(d)}+M(\theta(d)-\gamma(1-d)\}\right. \\
& \theta_{N R}=\frac{\hat{e} C^{\prime}(\hat{e})}{C(\hat{e})+F}, \text { where } m^{*}(d) \equiv \theta^{*}(d)-\gamma(1-d)>0 \text { and } \gamma \geq m^{*}(1)-m^{*}(0)>0 .
\end{aligned}
$$

b) The optimal wages contingent on the monitoring signal $I=\{H, L\}$ are: 


$$
\begin{aligned}
& w_{L}^{*}(d)=-F \\
& w_{H}^{*}(d)=C^{\prime}(\hat{e}) / P^{*^{\prime}}(\hat{e})-F
\end{aligned}
$$

Where, $P^{*}(\hat{e})=P\left(H / \theta^{*}(d)\right)$. When $\theta^{*}(d)=\theta_{N R}$, the worker does not obtain rents. The expected wages $\frac{\hat{e} C^{\prime}(\hat{e})}{\theta_{N R}}$ will be equal to the costs of effort. In the other case, $\theta^{*}(d)=\theta_{R}(d) \quad$, the worker obtains rents, $\frac{\hat{e} C^{\prime}(\hat{e})}{\theta_{R}(d)} \geq C(\hat{e})$

c) The optimal level of autonomy is:

$$
a^{*}= \begin{cases}1 & \text { if } B-\Delta^{*} \geq 0 \\ 0 & \text { otherwise. }\end{cases}
$$

Where $\Delta^{*}=T C^{*}(1)-T C^{*}(0)=\alpha /\left(\theta^{*}(1)\right)+M\left(m^{*}(1)\right)-\alpha /\left(\theta^{*}(0)\right)+M\left(m^{*}(0)\right)$ and $\alpha$ $\equiv \hat{e} C^{\prime}(\hat{e})$.

The contract establishes the consequences of all possible contingencies at the outset. In this sense, first autonomy is either provided to the worker, or not, based on the firm's and the worker's features. After autonomy has been provided, the state of nature regarding the feasibility of the innovation is revealed. Should the innovation prove feasible, and the worker has autonomy, it is always in her interest to introduce an innovation. The monitoring levels in the contract will be contingent to the fact that autonomy has been provided and the innovation is feasible. The firms will establish compensations based on 
the signal, whether low or high, that is finally generated about the worker's effort. Compensation differences between one case and another will be contingent to the provision of autonomy, the feasibility of the innovation and monitoring levels. In equilibrium the contract can display four different outcomes, no rent with no autonomy, no rent with autonomy, rent with no autonomy and rent with autonomy.

\subsection{Empirical implications}

In actual fact, the contract can be understood as a way of reproducing the series of decisions that will be made by the worker and the firm according to their expectations about the future at any particular stage. In the empirical applications, we will observe the decisions that are finally made and not a written contract about the level of autonomy $\left(a_{\mathrm{i}}\right)$, monitoring $\left(m_{\mathrm{i}}\right)$ and rents $\left(r_{\mathrm{i}}\right)$ established by the firm $i$. This rationale justifies the joint analysis of these key variables of the organization's design.

Furthermore, in accordance with the model, these decisions are made in the following sequence. First, autonomy is provided (or not), then the firm invests in monitoring, and finally the compensation system is established. Although not modelled, shocks will presumably appear between these decisions. These shocks affect future decisions, but previous decisions cannot be reverted.

Consequently, monitoring $\left(m_{i}\right)$ will be established on the basis of previously realized variables, such as autonomy $\left(a_{i}\right)$ and other observed ( $x_{j i}$ a set of $\mathbf{J}$ control variables; $j=1$ ,...J described in the next section) or unobserved variables (random variables $\varepsilon_{m, i}$ ). Therefore, the following equation can be estimated for a sample of firms: 
$m_{i}=\eta a_{i}+\sum_{j=1}^{J} \psi_{j} x_{j i}+\varepsilon_{m, i}$

where the $\eta$ and $\psi$ 's are the parameters to be estimated.

Furthermore, at the time compensation $\left(r_{i}\right)$ is determined, autonomy and monitoring have already been implemented. The structure of the theoretical model thus suggests the estimation of a recursive system of equations configured by (6) and the following equation:

$r_{i}=\beta_{1} a_{i}+\beta_{2} m_{i}+\sum_{j=1}^{J} \xi_{j} x_{j i}+\varepsilon_{r, i}$

where $\beta$ 's and $\xi$ 's are parameters to be estimated. Note that, in Equation (7), the variable monitoring is endogenous $\left(\mathrm{E}\left(\varepsilon_{r, i} / m_{i}\right)=\mathrm{g}\left(m_{i}\right) \neq 0\right)$ whenever the correlation of the error terms of the equations $\rho$ is not null. Previous literature analyzing the relationship between rents and monitoring (reviewed in the next section) did not take into account that autonomy (the selection of the task to be executed) will affect monitoring (the investment to monitor how much effort has been exerted in the execution of the task) and, based on that, compensation will be established. Most of the variables affecting one decision will thus affect the subsequent ones.

Sources of firm's heterogeneity are needed in order to formulate predictions about the parameters to be estimated. To focus the discussion, we are going to assume that firms differ only in terms of two types of shocks (the rest of the exogenous variables in the model are the same for all the firms). One type of shock affects the private benefits $B$ and 
occurs just before the autonomy decision has to be made. This shock introduces differences in private benefits across firms. A second shock affects the monitoring cost functions of firms and may occur after autonomy has been granted but before the monitoring is implemented. This shock introduces differences in the marginal costs of monitoring among firms and autonomy (or centralization) cannot be reverted after the shock is produced ${ }^{8}$. In Appendix 2 we extend this assumption more formally and incorporate it into the model. For the sake of simplicity, we present the simplified version of this model in the text.

The first kind of shock, changes in $B$, only has consequences in Proposition 1c, implying that different firms provide different levels of autonomy. For those firms not providing autonomy $\left(B<\Delta^{*}\right)$, according to Proposition 1a, the monitoring level $\left(m^{*}(0)\right)$ will never be higher than the level implemented by those firms providing autonomy. A percentage $(1-\lambda)$ of the firms that have provided autonomy $\left(B \geq \Delta^{*}\right)$ will not introduce innovations $(d=0)$, so they will have the same levels of monitoring $\left(m^{*}(0)\right)$. The remaining $(\lambda)$ percentage of cases will introduce innovations $(d=1)$, and therefore have higher levels of monitoring, $m^{*}(1)-m^{*}(0)>0$. If we cannot control for the fact that an innovation has been introduced in the workplace, then the expected monitoring level in firms that provide autonomy $\left(\lambda\left(m^{*}(1)-m^{*}(0)\right)+m^{*}(0)\right)$ will be higher than in firms without autonomy, $m^{*}(0)$. The model then predicts that the higher the autonomy for selecting the task developed, the higher the investment devoted to monitoring the execution of this task. The following hypothesis summarizes this relationship.

\footnotetext{
${ }^{8}$ A complete contract could be written contingent on this shock, but the task has to be selected before the shock and it is extremely costly to change the task after the shock.
} 
Hypothesis 1: The level of monitoring will be higher in those firms that have provided autonomy $(\eta>0)$.

Observe that monitoring refers to the level of investment in monitoring, and not to the output of such investments: the quality of information. The cost-disadvantage of monitoring new tasks implies that the quality of the information finally obtained by those firms that delegate decision-making will not be superior to that obtained by other firms (from Proposition 1a: $\left.\theta *(1)-\theta *(0)=m^{*}(1)-m^{*}(0)-\gamma \leq 0\right)$, even if they invest more in monitoring.

Note that the differences in monitoring will always be higher than the differences in the quality of information $\left(m *(1)-m^{*}(0)-\left(\theta^{*}(0)-\theta *(1)\right)=\gamma>0\right)$. Indeed, there will only be differences in the quality of information when workers obtain rents when an innovation is introduced (Propositions 1a and $1 \mathrm{~b}$ ). In these cases, an inferior quality of information and higher expected rents and monitoring levels is predicted than in those firms that continue with the customary tasks. Therefore, in these particular cases (in which workers obtain rents when innovation tasks are selected), the shocks in private profits also imply a positive correlation between rents and monitoring. As monitoring is also positively correlated to autonomy, it also implies a positive correlation between rents and autonomy.

These relationships, however, are not clear once additional shocks in monitoring costs arise after a task has been chosen. We are now in a context similar to Demougin and Fluet (2001). Such costs imply that firms, even those with the same level of autonomy, will have different monitoring levels. From Proposition $1 \mathrm{~b}$ we expect that, having selected a task $(d), \quad$ in firms with lower levels of monitoring 
$\left.m_{R}(d)=\theta_{R}(d)+\gamma(1-d) \leq m_{N R}(d)=\theta_{N R}+\gamma(1-d)\right)$ workers will obtain rents (and these rents will decrease with monitoring levels) whereas, when the monitoring levels are sufficiently high $\left(m_{R}(d)>m_{N R}(d)\right)$, workers will not obtain rents. The hypothesis below summarizes the preceding discussion, assuming that the monitoring shocks are the predominant source to explain the relationship between rents and the remaining variables.

Hypothesis 2: Workers' rent will be higher in those firms that have lower levels of monitoring $\left(\beta_{2}<0\right)$.

Take note that, if there are only the two shocks described above, the differences in workers' rents across firms are completely explained by differences in monitoring investment. Therefore, after controlling for monitoring, we will not expect any relationship between rents and autonomy $\left(\beta_{1}=0\right)$. This is trivial in contracts displaying no worker's rents in equilibrium. When rents exist, their variations are driven by shocks in the monitoring costs.

We do not have clear predictions for the correlation between the error terms $(\rho)$ of the equations above. One could argue that a shock increasing the monitoring investment also increases the probability of obtaining a good signal and receiving high compensation. As the observed rents $\left(w_{H}\right.$ or $\left.w_{L}\right)$ will be different to the expected rents in the model, one could suggest a positive correlation between the error terms of the equations above.

\subsection{Related evidence and control variables}


The evidence from the empirical analysis of the determinants of wages is overwhelming. The literature provides several examples of efforts attempting to provide empirical evidence of the negative relationship between compensation and monitoring ${ }^{9}$, which has typically been interpreted as evidence of the efficiency wage model (Shapiro and Stiglitz 1984).

Using this theoretical benchmark, Gordon (1994) and Georgiadis (2013) analyse the determinants of monitoring, of which there is much less extensive evidence (Neal 1993, Osterman 1994). Furthermore, some studies have interpreted monitoring as being the opposite concept to autonomy (Neal 1993), and thus the relationship between monitoring and autonomy remains unexplored.

The model developed helps to clarify these concepts. In the model, autonomy refers to the decision of selecting a task, and monitoring to the supervision of the task execution. The model makes predictions about the expected relationship between them. Furthermore, the theoretical benchmark developed suggests the need for a simultaneous empirical analysis of the determinants of workers' monitoring and compensation in order to control for omitted variables that could affect both decisions at the same time. As far as we know, this simultaneous analysis is restricted to Georgiadis (2013), who uses it to analyse the introduction of the national minimum wage legislation on wages and supervision, and where autonomy does not play any role.

In order to provide this analysis we are going to control for variables related to the characteristics of the workforce and the job place, labor relations and company environment. The cited empirical literature has emphasized that those variables could be related to workers' monitoring and compensation levels. It is far from our purposes to provide a complete description of the variables used previously. The justification of

\footnotetext{
9 Leonard (1987), Groshen and Krueger (1989), Neal (1993), Rebitzer (1995), Arai (2003), Ewing and
} Wunnava (2004). 
control variables set out below focuses on those variables on which we have collected information.

With regard to the workforce, we have collected information on the way it fits in with the job and the organization (Sekiguchi 2004). To proxy the concept of person-job fit, the literature has used variables such as skill requirements (Adams 2002), educational level (Neal 1993, Nagar 2002), experience (Neal 1993) or training (Rebitzer 1995). On the other hand, following the personnel psychology literature, the concept of personorganization fit can be proxied by the soft skill requirements (Schneider et al. 1995, Kristof 1996). The literature suggests a negative association between the fitting levels and monitoring, in fact there is evidence of this relationship between levels of skills (Osterman 1994), experience and education (Neal 1993) and monitoring. Furthermore, earlier scholarly works suggests a positive association between the level of skills (Earle 2009), schooling (Arai 2003), experience (Altonji and Shatokvo 1987, Arai 2003) and training (Rebitzer 1995) and the level of wages paid to the workers.

With regard to the workplace, we collected information on the complexity of the job position, the size of the plant, whether the firm is a single-plant or multi-plant, and the plant's technological intensity. Job complexity is a variable that has attracted the attention of scholars in the last few years as a determinant of the organizational design (Ben-Ner at al. 2012). The inclusion of variables related to the size of the firm or business unit is standard in the literature because of their effects on all organizational design choices (Nagar 2002). Overall, the literature provides evidence of a negative correlation between size and monitoring (Osterman 1994, Ewing and Wunnava 2004). On the other hand, most empirical studies provide evidence of a positive association between the size of the firm and the level of wages (Brown and Medoff 1985, Rebitzer 1995, Arai 2003, Ewing and Wunnava 2004). We also control for the existence of additional plants 
belonging to the same headquarters because the decisions related to organizational design might be made by them instead of by the plant managers (Foss and Laursen 2005). Lastly, controlling for industry is also a common practice in the literature (DeVaro and Kurtulus 2010, Ben-Ner et al. 2012) because each industry type has particular characteristics in terms of technology or capital intensity (Foss and Laursen 2005), with possible effects on the variables in the organizations design.

In reference to labor relations, we collected information about the presence of unions, collective bargaining agreements and job stability policies. Similar variables have been considered in many studies dealing with wages ${ }^{10}$ and the intensity of monitoring (Neal, 1993 and Gordon, 1994). In most cases this literature provides mixed results. There seems to be only a certain consensus on a negative correlation between the degree to which firms monitor workers and job stability (Gordon 1994, Osterman 1994, Neal 1993).

Regarding the environment in which firms operate, we obtained information about the degree of market competition and the uncertainty of the environment. The empirical literature provides evidence of a negative association between the level of wages and competition in the product market (Dickens and Katz 1987, Krueger and Summers 1987, Nickell, Vainomiaki and Wadhwani 1993). There has been a huge debate with mixed evidence on the role of uncertainty on wages (see Prendergrast, 2002). Recent research (Ben-Ner et al. 2012) has postulated that uncertainty has effects on other variables of the organizational design. We therefore consider that this could also be the case for monitoring.

\section{Empirical approach}

\footnotetext{
${ }^{10}$ Groshen and Krueger (1990), Osterman (1994), Altonji and Williams (1997), Arai (2003).
} 


\subsection{Data}

The data for testing the hypotheses is taken from a survey ${ }^{11}$ designed to obtain information on the human resources and work organization practices of Spanish industrial establishments. The original questionnaire was fine-tuned with a pre-test sample of 15 plant directors. The use of subjective assessments by the interviewee on various scales is a common practice in the empirical literature concerned with the analysis of human resources and work organization practices. This approach allows for the possibility of obtaining information on certain concepts even if objective information is not available.

The target group was a collection of manufacturing establishments in mainland ${ }^{12}$ Spain with 50 or more workers and whose economic activity was included in one of the 13 manufacturer sectors of the NACE classification for $1993 .{ }^{13}$ The unit of observation is the establishment, not the firm as a whole. The sample of firms or manufacturing plants was identified in CAMERDATA (the database for the chamber of commerce of Spain) and consisted of 3,000 plants. A stratified random sample, guaranteeing stratums by size and industrial sector, based on 402 interviews (13.5\% of the target group) was finally achieved. A questionnaire form was filled in for each establishment between December 2007 and April 2008, using personal interviews approximately 60 minutes long carried out by a specialized firm, in most cases with the directors or with the production or human

\footnotetext{
${ }^{11}$ The survey was jointly designed by a group of researchers from the Universitat Autònoma de Barcelona, Universitat Illes Balears, Universidad Pública de Navarra, and Universidad de Zaragoza. The questionnaire can be provided on request.

${ }^{12}$ Due to budget restrictions, the Canary and Balearic Islands as well as the two smallest (in terms of per capita GDP) Autonomous Communities, Castilla La Mancha and Extremadura, were excluded from the sample.

${ }^{13}$ The European Community statistical classification of economic activities.
} 
resources managers of the plant. ${ }^{14}$ Since some questionnaires were incomplete ${ }^{15}$, we ended up with 358 observations. Table 1 compares the distribution of the plants by size and economic sector among the population of Spanish manufacturing establishments ${ }^{16}$ and the sample. As we can see, overall the percentages or quotes for each category are very close, indicating no sampling selection bias problems, at least by the variables for which we can control.

-Insert Table 1-

\subsection{Variables}

The first column of Table 2 shows the original questions from which we define the variables used in the estimations. As Neal (1993) suggests, monitoring can be interpreted as the opposite concept to autonomy. In the theoretical section two decisions have to be monitored and delegated, the selection and the effort in the execution of a task. We use the word autonomy when we refer to the selection of the task and the word monitoring when we refer to the execution of the task. The definition of the variables from the questionnaire suggests that this is also the sense of the questions used to measure these two variables. Furthermore, monitoring refers to the efforts made by the firm to monitor its workers (respondents assess whether on performing their job, workers are extensively supervised) and not to the results of such efforts or information quality. With the

\footnotetext{
${ }^{14}$ Interviewer status was required by the questionnaire. Specifically, there are 9 possibilities: single owner ( $1 \%$ of the sample), partner or co-owner (3.4\% of the sample), chairperson ( $2 \%$ of the sample), director or general manager ( $13.8 \%$ of the sample), sole director of a limited liability company ( $11.6 \%$ of the sample), plant manager (9\% of the sample), production manager (13.5\% of the sample), human resources manager ( $17.8 \%$ of the sample) and others ( $32 \%$ of the sample).

${ }^{15}$ The missing values are spread throughout the different variables of the sample.

${ }^{16}$ The population data are taken from the Central Directorate of Companies (Directorio Central de Empresas--DIRCE) of the Spanish National Statistics Institute (Instituto Nacional de Estadística de España-INE).
} 
exception of a continuous variable, plant Size, and three binary answers, the industrial sector, the presence of Collective agreement and whether the firm has a Multi-plant structure, the variables have been constructed on the basis of the degree of agreement of the interviewed on certain assertions. The degree of agreement is measured using a Likert scale from 1 to 5 .

--Insert table 2 about here-

The dependent variables in Equations 6 and 7, Monitoring and Rents, are originally measured as ordinal variables. For the case of Rents there are no answers for category 5 , so we will consider just four categories. Further information about the distribution of these variables is provided in Table 3. The contingent distribution of these variables according to the level of autonomy provided by the firm suggests a positive relationship between autonomy and monitoring (Hypothesis 1) and a negative one between rents and autonomy.

--Insert table 3 about here-

Working with ordinal variables when they are used as independent variables causes problems in empirical applications. The proper use of those variables as explanatory ones implies including four dummies related with each item in the estimations. A problem with this procedure is that some of the categories have very few observations, causing colinearity in the estimations. In order to avoid such problems, and for the sake of expositional simplicity, we proceed to construct one dummy for each ordinal variable. This requires the selection of a category cut-off. Some studies (e.g. Foss and Laursen 
2005) have used the original medium category (value 3 in our case) for this purpose. The application of this procedure in our data provides highly skewed distributions for certain variables. We therefore followed an alternative procedure, which is some form of standardization: the cut-off will be the category closest to representing the median for the distribution of the variable. We thus proceeded to group the adjacent original categories with the aim of finally obtaining two categories with the most egalitarian distribution possible for the observations. Following this method, we create the binary variables: Autonomy, Union influence, Market competition, Job stability, Technological intensity and Soft skill requirements.

A challenge is presented when more than 50 percent of the observations were concentrated in the original medium category (value 3). In those cases, we consider three categories (two dummy variables), but only if each resulting category comprises at least 10 percent of the observations. This is the case for the variables Qualification requirements, Uncertainty and Training.

The questionnaire contains 6 statements related to degree of complexity in the production process (see the definitions in Table 2). In particular, these statements refer to the number of products produced, to the modifications made to the products, and to product turnover, which presumably increase the number of activities performed by the worker and therefore resemble the concept of complexity considered by Prendergast (2002). We applied the principal component factor analysis to summarize this information. The application of this technique resulted in one factor with a Cronbach alpha of 0.75 . This index will be considered in the analysis as our measure of Job complexity. By construction this variable has a mean of zero and standard deviation of 1. A summary of the variables defined in this section can be found in the last columns of Table 2 . 


\subsection{Econometric models}

In accordance with the original questions, the variables Monitoring and Rents are ordinal with five and four categories, respectively. Therefore, the model to be estimated is as follows:

$$
\begin{aligned}
& m_{i}^{*}=\eta a_{i}+\sum_{j=1}^{J} \psi_{j} x_{j i}+\varepsilon_{m, i} \\
& r *_{i}=\beta_{1} a_{i}+\beta_{2} m_{i}+\sum_{j=1}^{J} \xi_{j} x_{j i}+\varepsilon_{r, i}
\end{aligned}
$$

Where $m_{i}{ }^{*}$ and $r_{i}{ }^{*}$ are latent variables. If we assume that the error terms of both equations are uncorrelated $(\rho=0)$, then we can estimate two independent order probit models (Model 1). Note, however, that the estimation of the effect of monitoring on rents --Equation (7)-- will suffer from endogeneity problems if the error terms are correlated ( $\rho \neq 0$ ). As far as we know, this recursive model (e.g. a bivariate model) in which both dependent and independent variables are ordinal has not been previously estimated (see Greene 2012, p.833).

The closest model already estimated is the semi-order bivariate probit model (Greene and Hensher 2009). To estimate this model, the variable Monitoring has to be transformed into a binary variable, which is included as the dependent variable in Equation (6) and as an independent variable in Equation (7). The estimator of the relationship between rents and monitoring that this methodology provides is a full information instrumental variable 
(Hausman, 1975), in the sense that it takes into account the possible correlation between disturbances and regressors, and between the disturbances of the two equations. The semiorder bivariate model (Model 2) also provides an estimation of the correlation between the error terms of both equations and allows us to perform an exogeneity test. If we cannot reject the null hypothesis that the error terms are uncorrelated, we cannot reject the assumption that monitoring is exogenous (Monfardini and Radice, 2008) and our preferred model would be Model 1 (otherwise it would be Model 2).

In the next section, we present the estimation of both models using robust standard errors. In Equation (7), Monitoring is always a dummy variable created using the same procedures applied for the rest of the independent variables. This is also the dependent variable in Equation (6) when we estimate Model 2, but in Model 1 we use it in an ordinal form.

\subsection{Results}

Table 4 shows the estimations of Models 1 and 2. At the 1 percent level, the likelihood ratio rejects the null hypothesis that all the explanatory variables are zero in both models. The correlation coefficient estimated in Model 2 is positive but not statistically significant, so the Wald test of independency between equations (6) and (7) cannot reject the null hypothesis that the error terms are uncorrelated $(\rho=0)$.

Thus, we will focus first on the results obtained from the estimation of our preferred specification, Model 1. The estimation of Equation 6 provides strong support for Hypothesis 1. The coefficient of the variable Autonomy is positive and statistically different from zero at the 1 percent level. In this estimation, there are four additional 
variables that play a role in determining the extent of workers' monitoring. The variable Soft skill requirements has a positive and statistically significant effect (at 2 percent level) on Monitoring. Technological intensity, Collective agreements and Job stability have a negative and statistically significant effect (at 4, 3 and 4 percent levels, respectively) on Monitoring.

The second column of Model 1 shows the results of the estimation of Rents, Equation (7). Hypothesis 2 also receives support. The coefficient of the variable Monitoring is negative and statistically significantly different from zero at the four percent level. From the remaining coefficients, there is an array of variables playing a role in determining the level of Rents. The coefficient of the variable Job complexity is negative and statistically significantly different from zero at the $9 \%$ level. The variables Medium training, High training, Multiplant, Unions influence and Collective agreements are positive and statistically significant at 7, 1, 7, 1 and 9 percent level, respectively.

-Insert Table 4 about here-

The main difference between the coefficients estimated in Models 1 and 2 is the magnitude of the effect of Monitoring on Rents. It seems that if there were endogeneity problems in the estimations of Model 1, we would be underestimating the negative effect of Monitoring on Rents in Equation (7), due to the positive correlation between the error terms of both equations (although not statistically significant).

Furthermore, in Model 2 some of the variables that were statistically significant in Model 1 lose their significance. This is the case of Job complexity and Collective agreement in Equation (7) and Technological intensity in Equation (6). 
We have estimated other models (not reported in the text), modifying the categorization of the dependent and independent variables, and the main conclusions regarding Hypotheses 1 and 2 are maintained.

\section{Conclusion and discussion}

This paper suggests that providing autonomy to the workforce implies higher investments in monitoring the new tasks that workers could introduce in the workplace as a consequence of their discretion. A theoretical model is developed for understanding the implications of this assumption for the way in which autonomy, monitoring and compensation policies of firms interact. The paper provides empirical evidence supporting the main predictions of the model.

The theoretical model has important managerial implications for those firms that would like to provide autonomy to their workers in order to take advantage of their better knowledge of the workplace. Autonomy creates room for workers to introduce innovative tasks into the workplace. These innovative tasks require higher investments in the monitoring systems aimed at collecting information about the workers' performance. In order to provide incentives to workers, firms must link wages to the information collected about their performance.

In more formal terms, new tasks will imply higher monitoring levels in order to induce the same level of effort from workers as in customary tasks. Therefore, given this higher cost, it could be perfectly possible that some firms centralize decisions even if autonomy generates private profits to the firm. Once firms have decided on the level of autonomy to be provided, shocks in the monitoring costs could cause firms with the same levels of autonomy to provide different monitoring and rent combinations. Monitoring and rents 
are substitutes in the production of effort, which implies a negative association between current levels of monitoring and rents.

Some of these arguments have already been discussed individually in the theoretical literature. For example, Prendergrast (2002) suggests that firms can take advantage of the workers' better information about the workplace by providing them with autonomy. Demougin and Fluet $(1998,2001)$ make an effort to understand the relationship between investment decisions on monitoring and the wage policy.

Bolton and Dewatripont (2012) summarizes a body of literature analyzing autonomy as a mechanism for enhancing the effort to provide information to aid the taking of decisions. Our contribution is to introduce into the analysis of organizations the interrelationship between monitoring the execution of the task and autonomy for selecting the task to be executed. This connection allows us to analyze the way in which three key variables of the job design, autonomy, monitoring and compensation, are related. To the best of our knowledge, this modelling has not been done before.

The model is inspired by the anecdotal evidence about the relationship between the variables of the job design analyzed here. It generates several empirical implications. If firms behave according to the model, they will decide the level of autonomy by taking into account the predictions of the future levels of monitoring and wages. However, the final level of monitoring will be contingent to the level of autonomy granted and the random shocks that might affect monitoring costs. As far as we are aware, there is no empirical analysis of this relationship. In a similar way, wages are established based on optimal monitoring levels. The theoretical model suggests that exogenous variables will affect monitoring and rents at the same time; therefore, it is important to test the presence of endogeneity problems affecting the estimation of the impact of monitoring on rents. 
To test the empirical implications of the model, we use a sample of 358 Spanish industrial plants. The results confirm the main hypotheses of the model, monitoring is positively related to autonomy and rents are negatively related to monitoring. Furthermore, there is no relation between autonomy and rents in the estimations reported in the paper. Although there is extensive evidence on the negative relationship between monitoring and rents (Leonard 1987, Groshen and Krueger 1989, Neal 1993, Rebitzer 1995), Arai (2003), Ewing and Wunnava (2004), Gordon 1994, Georgiadis 2012), the other pieces of evidence are new to the literature.

Moreover, we also report a strong positive relationship between training and the importance of unions on rents, which are very intuitively appealing. Other results also show that contractual arrangements, such as the presence of Collective agreements or Job Stability, are associated with lower levels of monitoring. On the other hand, job requirements, such as Soft skills, enhance the need for monitoring.

Obviously the paper is not free of shortcomings that future research could overcome. For example, new methodological developments will let us to control for endogeneity problems in recursive models with an order dependent and independent variable. Although we do not have clear arguments suggesting that the empirical evidence comes from a very special context, only further evidence can show whether our results are replicated (or not) in other countries and periods of time. There is room for improvement in the measurement of different theoretical concepts. Information on innovations in the work place, the cost cuts that such innovation implies and detailed information on monitoring investments will help to improve the tests of the model and enrich the theoretical debate. 


\section{REFERENCES}

Adams, C. P., 2002, “Agent Discretion, Adverse Selection and the Risk-Incentive Trade-off,” Working Paper No. 255, FTC Bureau of Economics.

Aghion, P. and J. Tirole, 1997, "Formal and Real Authority in Organizations," Journal of Political Economy, 105(1), 1-29.

Altonji, J. and R. Shakotko, 1987, “Do Wage Rises with Job Seniority?” Review of Economic Studies, 54 (3), 437-459.

Altonji, J. and N. Williams, 2005, "Do Wages Rise With Seniority? A Reassessment," Industrial and Labor Relations Review, 58(3), 370-397.

Arai, M., 2003, "Wages, Profits, and Capital Intensity: Evidence from Matched Work-Firm Data," Journal of Labor Economics, 21(3), 593-618.

Ben-Ner, A., F. Kong and S. Lluis, 2012, "Uncertainty, Task Environment and Organization Design," Journal of Economic Behavior and Organization, 82(1), 281-313.

Bolton P. J. and M. Dewatripont, 2012, “Authority in Organizations,” Gibbons R. and J. Roberts, ed., Handbook of Organizational Economics.

Brown, C. and J. Medoff, 1989, "The Employer Size-Wage Effect," Journal of Political Economy, 97(5), 1027-59.

Collins J. and J. I. Porras, 1994, "Built to last: Successful habits of visionary companies," Harper Collins, New York.

Demougin, D. and C. Fluet, 1998, "Mechanism Sufficient Statistic in the RiskNeutral Agency Problem," Journal of Institutional and Theoretical Economics (JITE), 154(4), 622 .

Demougin, D. and C. Fluet, 2001, "Monitoring versus Incentives," European Economic Review, 45(9), 1741-1764. 
Dessein, W., 2002, “Authority and Communication in Organizations,” Review of Economic Studies, 69, 811-838.

DeVaro, J. and F. A. Kurtulus, 2010, “An Empirical Analysis of Risk, Incentives, and the Delegation of Worker Authority," Industrial and Labor Relations Review, 63(4), 641-661.

Dickens, W. T. and L. F. Katz, 1987, "Industry and Occupation Wage Patterns and Theories of Wage Determination," Lang, K. and J. Leonard, ed., Unemployment and the Structure of Labor Markets, Oxford: Blackwell.

Earle, D., 2010, "Skills, qualifications, experience and the distribution of wages," Tertiary Sector Performance Analysis and Reporting, Strategy and System Performance, Ministry of Education of New Zealand.

Ewing, B. and P. Wunnava, 2004, "The Trade-Off between Supervision Cost and Performance Based Pay: Does Gender Matter?” Small Business Economics, 23(5), 453460.

Foss, N. J. and K. Laursen, 2005, "Performance Pay, Delegation and Multitasking Under Uncertainty and Innovativeness: An Empirical Investigation," Journal of Economic Behavior \& Organization, 58, 246-276.

Georgiadis, A., 2013, "Efficiency Wages and the Economic Effects of the Minimum Wage: Evidence from a Low-Wage Labour Market," Oxford Bulletin of Economics and Statistics, 75 (6), 962-979.

Gordon, D. M., 1994, “Bosses of Different Stripes: A Cross-National Perspective on Monitoring and Supervision," The American Economic Review, 84(2), 375-379.

Greene, W. H., 2012, “Econometric Analysis: International Edition”. $7^{\mathrm{TH}}$ Edition. Pearson Education Limited, Essex, England. 
Greene, W. H. and D. A. Hensher, 2009, Modeling Ordered Choices: A Primer. Mimeo, Stern School of Business, New York.

Groshen, E. and A. B. Krueger, 1990, "The Structure of Supervision and Pay in Hospitals,” Industrial and Labor Relations Review, 43(3), 134-146.

Hamel, G. and B. Breen, 2007, "Creating a Community of Purpose: Whole Foods Market: Management Innovation in Action," Harvard Business Press Chapters.

Hausman, J., 1975, “An Instrumental Variable Approach to Full Information Estimators for Linear and Certain Non Linear Econometric Models," Econometrica, 43(4), 727-738.

Holmström, B., 1979, "Moral Hazard and Observability," Bell Journal of Economics, 10(1), 74-91.

Kaplan, R. S. and D. P. Norton, 2001, "The Strategy-Focused Organization," Harvard Business School Press, Boston, Massachusetts.

Kim, S., 1997, "Limited Liability and Bonus Contracts," Journal of Economics and Management Strategy, 6 (4), 899-913.

Kristof, A. L., 1996, "Person-organization Fit: An Integrative Review of Its Conceptualizations Measurement, and Implications," Personnel Psychology, 49(1), 1-49.

Krueger, A. B. and L. H. Summers, 1987, "Reflections on the Inter-Industry Wage Structure," Lang, K. and J. Leonard, ed., Unemployment and the Structure of Labor Markets, Oxford: Blackwell.

Landau, R. and N. Rosemberg, 1986, National Research Council. The Positive Sum Strategy: Harnessing Technology for Economic Growth. Washington, DC: The National Academies Press.

Leonard, J. S., 1987, “Carrots and Sticks: Pay, Supervision and Turnover.” Journal of Labor Economics, 5(4), 136-152. 
Maddala, G. S., 1983, Limited Dependent and Qualitative Variables in Econometrics. Cambridge University Press: Cambridge.

Monfardini, C. and R. Radice, 2008, “Testing Exogeneity in the Bivariate Probit Model," Oxford Bulletin of Economics and Statistics, 70(2), 271-282.

Nagar, V., 2002, "Delegation and Incentive Compensation." The Accounting Review, 77(2), 379-395.

Neal, D., 1993, "Supervision and Wages Across Industries," The Review of Economics and Statistics, 75(3), 409-417.

Nickell S., J. Vainomiaki and S. Wadhwani, 1993, "Wages and Product Market power," Economica, New series, 61(244), 457-473.

Osterman, P., 1994, "Supervision, Discretion and Work Organization." The American Economic Review, papers and proceedings, 84(2), 380-384.

Prendergast, C., 1999, "The Provision of Incentives in Firms," Journal of Economic Literature, 37(1), 7-63.

Prendergast, C., 2002, "The Tenuous Trade-off between Risk and Incentives," Journal of Political Economy, 110(5), 1071-1102.

Rebitzer, J. B., 1995, "Is there a tradeoff between supervision and wages? An empirical test of efficiency wage theory," Journal of Economic Behaviour and Organization, 28 (1), 107-129.

Saint Paul, G., 1996, "Dual Labor Markets: A Macroeconomic Perspective,” MIT press.

Schneider B., H. W. Goldstein and D. B. Smith, 1995, "The ASA Framework: An Update,” Personnel Psychology, 48(4), 747-773.

Sekiguchi, T., 2004, "Person-Organization Fit and Person-Job Fit in Employee Selection: A Review of the Literature," Osaka Keidai Ronshu, 54(6), 179-196. 
Shapiro, C. and J. E. Stiglitz, 1984, "Equilibrium Unemployment as a Worker Discipline Device," American Economic Review, 74(3), 433-44

Shavel, S., 1979, "Risk Sharing and Incentives in the Principal and Agent Relationship,” Bell Journal of Economics, 10(1), 55-73.

Wilde, J., 2000, "Identification of Multiple Equation Probit Models with Endogenous Dummy Regressors," Economic Letters, 69 (3), 309-312. 


\section{Figure 1. Model Timeline}

\begin{tabular}{|c|c|c|c|c|}
\hline $\begin{array}{c}\text { Stage 0 } \\
\end{array}$ & Stage 1 & Stage 2 & Stage 3 & Stage 4 \\
\hline $\begin{array}{l}\text { Firm and workers: } \\
\text { Observe the firm's } \\
\text { private benefits } \\
\text { from introducing } \\
\text { innovation } B \text {. } \\
\text { Know the } \\
\text { probability } \lambda \text { that } \\
\text { an innovative task } \\
\text { will be feasible } \\
\text { when the worker } \\
\text { will be allocated } \\
\text { to the workplace }\end{array}$ & $\begin{array}{l}\text { The firm offers a } \\
\text { contract. } \\
\text { The worker } \\
\text { accepts or rejects } \\
\text { it. }\end{array}$ & $\begin{array}{l}\text { The worker: } \\
\text { Observes whether } \\
\text { an innovative task } \\
\text { is feasible or not. } \\
\text { Decides if he or } \\
\text { she should } \\
\text { innovate }(d=1) \text { or } \\
\text { not }(d=0) \text {. }\end{array}$ & $\begin{array}{l}\text { The firm: } \\
\text { Invests in } \\
\text { monitoring the } \\
\text { task with intensity } \\
m \text {. }\end{array}$ & $\begin{array}{l}\text { The worker exerts } \\
\text { effort } e \\
\text { Firm and workers } \\
\text { observe worker's } \\
\text { performance, } I=H \\
\text { or } I=L \text {. } \\
\text { Payments based } \\
\text { on worker's } \\
\text { performance are } \\
\text { made }\end{array}$ \\
\hline
\end{tabular}


Table 1

Distribution of the Plants by Size and Economic Sector

\begin{tabular}{|c|c|c|c|}
\hline Variable & Category & $\begin{array}{c}\% \\
\text { Sample }\end{array}$ & $\begin{array}{c}\% \\
\text { Population } \\
\end{array}$ \\
\hline \multirow[t]{5}{*}{ Size } & From 50 to 99 employees & 47.49 & 55.07 \\
\hline & From 100 to 199 employees & 33.52 & 24.39 \\
\hline & From 200 to 499 employees & 13.97 & 15.22 \\
\hline & More than 500 employees & 5.03 & 5.32 \\
\hline & Total & 100 & 100 \\
\hline \multirow[t]{14}{*}{ Industry } & Food, drink and tobacco & 16.48 & 16.05 \\
\hline & Textile industry, dressmaking, leather and footwear & 8.66 & 6.39 \\
\hline & Wood, cork, paper and graphic arts & 10.06 & 10.96 \\
\hline & Furniture and various manufacturing industries & 4.19 & 5.36 \\
\hline & $\begin{array}{l}\text { Rubber, plastic materials and non-metallic mineral } \\
\text { products }\end{array}$ & 19.83 & 16.21 \\
\hline & Machinery and metal equipment & 12.01 & 16.98 \\
\hline & Chemical industry & 3.07 & 5.54 \\
\hline & Mechanical equipment and machinery & 8.38 & 8.71 \\
\hline & Electric equipment & 3.07 & 3.86 \\
\hline & Motor vehicle and transport supply & 8.94 & 4.63 \\
\hline & Electronic, medical, optical and computer equipment & 2.79 & 2.78 \\
\hline & Pharmaceutical industry & 1.96 & 2.01 \\
\hline & Aeronautical industry & .56 & .48 \\
\hline & Total & 100 & 100 \\
\hline
\end{tabular}

The population of Spanish establishments is taken from the Central Directorate of Companies. In the sample the variable size is continuous but in the population the information about the size appears in categories. 


\begin{tabular}{|c|c|c|c|}
\hline Original questions & Variable & Type & Mean \\
\hline $\begin{array}{l}\text { Measures the salaries of the blue-collar workers } \\
\text { compared to the salaries of the blue-collar } \\
\text { workers of the direct competitors (Likert scale) }\end{array}$ & Rents & Likert & 2.3436 \\
\hline $\begin{array}{l}\text { Measures to what extent workers are supervised } \\
\text { when performing their job (Likert scale) }\end{array}$ & Monitoring & Likert & 3.2961 \\
\hline $\begin{array}{c}\text { Measures the level of autonomy (when, how and } \\
\text { in what order a task has to be implemented) that } \\
\text { the blue-collar worker has on performing their } \\
\text { job (Likert scale) }\end{array}$ & Autonomy & Dummy & 0.6089 \\
\hline $\begin{array}{l}\text { 1) A large number of products are made in your } \\
\text { plant, 2) The products made in the plant are very } \\
\text { different from each other, 3) The mixture of } \\
\text { products made in the plant can easily be changed, } \\
\text { 4) Many new products are introduced each year, } \\
\text { 5) The new products are usually very different } \\
\text { from the existing ones, 6) The products we } \\
\text { produce undergo continuous modifications }\end{array}$ & Job complexity & $\begin{array}{l}\text { Continuous: } \\
\text { Factorial } \\
\text { analysis }\end{array}$ & 0 \\
\hline \multirow{2}{*}{$\begin{array}{l}\text { The level of qualification required for the plant's } \\
\text { blue-collar workers to perform the job (Likert } \\
\text { scale) }\end{array}$} & $\begin{array}{l}\text { Medium Skill } \\
\text { requirements }\end{array}$ & Dummy & 0.6229 \\
\hline & High Skill requirements & Dummy & 0.1788 \\
\hline \multirow{2}{*}{$\begin{array}{l}\text { Evaluates investment in human capital in terms of } \\
\text { both hours and money (Likert scale) }\end{array}$} & Medium training & Dummy & 0.5587 \\
\hline & High training & Dummy & 0.2933 \\
\hline $\begin{array}{c}\text { Plant's selection criterion takes into consideration } \\
\text { workers' learning capabilities, interpersonal } \\
\text { abilities, cultural adjustment, attitudes, and even } \\
\text { the personalities (Likert scale) }\end{array}$ & Soft skill requirements & Dummy & 0.7458 \\
\hline Number of workers & Size & Continuous & 205 \\
\hline $\begin{array}{l}\text { The firm has plants in addition to the one being } \\
\text { interviewed, either in Spain or abroad (Binary } \\
\text { answer) }\end{array}$ & Multi-plant & Dummy & 0.5587 \\
\hline Author's sector classification & Technological intensity & Dummy & 0.6034 \\
\hline $\begin{array}{l}\text { Assess unions' degree of influence on blue-collar } \\
\text { workers }\end{array}$ & Unions influence & Dummy & 0.3268 \\
\hline $\begin{array}{l}\text { There is a specific collective agreement that } \\
\text { regulates the labor conditions of blue-collar } \\
\text { workers (Binary answer) }\end{array}$ & Collective agreement & Dummy & 0.5865 \\
\hline $\begin{array}{l}\text { Solid commitment to maintaining employment } \\
\text { relationship with blue collar-workers indefinitely } \\
\text { (Likert scale) }\end{array}$ & Job stability & Dummy & 0.5168 \\
\hline $\begin{array}{l}\text { Evaluate degree of market competition faced by } \\
\text { the plants (Likert scale) }\end{array}$ & Market Competition & Dummy & 0.3520 \\
\hline \multirow{2}{*}{$\begin{array}{c}\text { Evaluate variability magnitude in demand from } \\
\text { year to year (Likert scale) }\end{array}$} & Medium Uncertainty & Dummy & 0.5726 \\
\hline & High Uncertainty & Dummy & 0.2821 \\
\hline
\end{tabular}


Table 3.

Distribution of rents and monitoring conditional to autonomy.

\begin{tabular}{|l|c|c|c|c|c|} 
& $\begin{array}{c}1 \\
\text { Total } \\
\text { disagreement }\end{array}$ & $\begin{array}{c}2 \\
\text { Disagreement }\end{array}$ & $\begin{array}{c}3 \\
\text { Neither agreement } \\
\text { nor disagreement }\end{array}$ & $\begin{array}{c}4 \\
\text { Agreement }\end{array}$ & $\begin{array}{c}5 \\
\text { Total } \\
\text { Agreement }\end{array}$ \\
\hline Rents & 9 & 224 & 118 & 7 & 0 \\
& $2.51 \%$ & $62.57 \%$ & $32.96 \%$ & $1.50 \%$ & $0 \%$ \\
\hline Rents conditional to Autonomy =1 & 4 & 154 & 54 & 6 & 0 \\
& $1.83 \%$ & $70.64 \%$ & $24.77 \%$ & $2.75 \%$ & $0 \%$ \\
\hline Rents conditional to Autonomy =0 & 5 & 70 & 64 & 1 & 0 \\
\hline Monitoring & $3.57 \%$ & $50.00 \%$ & $45.71 \%$ & $0.71 \%$ & $0 \%$ \\
\hline Monitoring conditional to Autonomy $=1$ & 10 & 63 & 116 & 149 & 20 \\
& $2.79 \%$ & $17.60 \%$ & $32.40 \%$ & $41.62 \%$ & $5.59 \%$ \\
\hline Monitoring conditional to Autonomy $=0$ & 2 & 23 & 65 & 119 & 9 \\
& $9.17 \%$ & $10.6 \%$ & $29.8 \%$ & $54.6 \%$ & $4.1 \%$ \\
\hline
\end{tabular}




\begin{tabular}{|c|c|c|c|c|c|c|c|c|}
\hline \multicolumn{5}{|c|}{ Model 1. Independent Ordered Probits } & \multicolumn{4}{|c|}{ Model 2. Semi-Ordered Probit } \\
\hline $\begin{array}{l}\text { Dependent } \\
\text { variables }\end{array}$ & \multicolumn{2}{|c|}{$\begin{array}{c}\text { Monitoring } \\
\text { Eq (6) } \\
\end{array}$} & \multicolumn{2}{|c|}{$\begin{array}{l}\text { Rents } \\
\text { Eq (7) }\end{array}$} & \multicolumn{2}{|c|}{$\begin{array}{c}\text { Monitoring } \\
\text { Eq (6) }\end{array}$} & \multicolumn{2}{|c|}{$\begin{array}{l}\text { Rents } \\
\text { Eq (7) }\end{array}$} \\
\hline $\begin{array}{l}\text { Independent } \\
\text { Variables } \\
\text { Monitoring }\end{array}$ & Estimates & $\begin{array}{c}p- \\
\text { values }\end{array}$ & $\begin{array}{l}\text { Estimates } \\
-29 * *\end{array}$ & $\begin{array}{c}p- \\
\text { values } \\
04\end{array}$ & Estimates & $\begin{array}{c}p- \\
\text { values }\end{array}$ & $\begin{array}{l}\text { Estimates } \\
-127 * *\end{array}$ & $\begin{array}{c}p- \\
\text { values } \\
02\end{array}$ \\
\hline Autonomy & $.44 * * *$ & .00 & -.22 & $\begin{array}{l}.04 \\
.20\end{array}$ & $.55 * * *$ & .00 & .004 & $\begin{array}{l}.02 \\
.98\end{array}$ \\
\hline Job complexity & .04 & .55 & $-.11 *$ & .09 & .04 & .57 & -.09 & .17 \\
\hline $\begin{array}{l}\text { Medium Skill } \\
\text { requirements }\end{array}$ & .20 & .26 & .01 & .96 & .21 & .30 & .08 & .64 \\
\hline $\begin{array}{l}\text { High Skill } \\
\text { requirements }\end{array}$ & .07 & .76 & -.09 & .73 & -.14 & .57 & -.10 & .65 \\
\hline $\begin{array}{l}\text { Medium } \\
\text { training }\end{array}$ & -.26 & .14 & $.40^{*}$ & .07 & -.22 & .31 & .28 & .19 \\
\hline High training & -.28 & .19 & $.97 * * *$ & .00 & -.16 & .52 & $.79 * * *$ & .00 \\
\hline $\begin{array}{l}\text { Soft skill } \\
\text { requirements }\end{array}$ & $.35 * *$ & .02 & -.03 & .83 & $.41 * *$ & .2 & .12 & .51 \\
\hline Size & -.00003 & .64 & -.0001 & .52 & -.0003 & .14 & -.0001 & .31 \\
\hline Multi-plant & .01 & .91 & $.25^{*}$ & .07 & .04 & .76 & $.24 *$ & .08 \\
\hline $\begin{array}{l}\text { Technological } \\
\text { intensity }\end{array}$ & $-.25 * *$ & .04 & .05 & .71 & -.03 & .84 & -.03 & .83 \\
\hline $\begin{array}{l}\text { Unions } \\
\text { influence }\end{array}$ & .03 & .82 & $.38 * * *$ & .00 & -.10 & .52 & $.31 * *$ & .04 \\
\hline $\begin{array}{l}\text { Collective } \\
\text { agreement }\end{array}$ & $-.27 * *$ & .03 & $.25^{*}$ & .09 & $-.29 *$ & .05 & .11 & .52 \\
\hline Job stability & $-.25 * *$ & .04 & .09 & .52 & $-.26^{*}$ & .08 & -.01 & .93 \\
\hline $\begin{array}{l}\text { Market } \\
\text { Competition }\end{array}$ & .01 & .92 & -.02 & .91 & .03 & .83 & -.01 & .95 \\
\hline $\begin{array}{l}\text { Medium } \\
\text { Uncertainty }\end{array}$ & -.21 & .21 & .14 & .48 & -21 & .31 & .06 & .76 \\
\hline $\begin{array}{l}\text { High } \\
\text { Uncertainty }\end{array}$ & -.01 & .96 & .12 & .62 & .03 & .88 & .12 & .56 \\
\hline Cutl & -2.23 & & -1.38 & & & & -1.63 & \\
\hline Cut2 & -1.01 & & 1.19 & & & & .63 & \\
\hline Cut3 & -.02 & & 3.07 & & & & 2.28 & \\
\hline Cut4 & 1.57 & & & & & & .17 & \\
\hline Chi2 & $50.84 * * *$ & .00 & $60.33 * * *$ & .00 & & & $73.27 * * *$ & .00 \\
\hline Pseudo R2 & .06 & & .09 & & & & & \\
\hline $\begin{array}{l}\text { Log likelihood } \\
\text { rho }(\rho)\end{array}$ & -438.72 & & -270.40 & & & & $\begin{array}{c}-491.11 \\
.62\end{array}$ & .38 \\
\hline 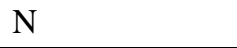 & 358 & & 358 & & & & 358 & \\
\hline
\end{tabular}




\section{Appendix 1. The model solution demonstration (Proposition 1).}

Proposition 1b)

The minimization of the objective function implies minimizing the cost function $\mathrm{TC}(d)$ subject to Restrictions 1 to $4 . w_{H} *(d)-w_{L} *(d)=C^{\prime}(\hat{e}) / P^{* \prime}(\hat{e})$ guarantees that the Incentive compatibility constraint (1) is fulfilled at the lower expected wages. The $w_{L}$ that guarantees the Interim participation constraint (3) and the Limited liability constraint (4) at the minimum expected wage is the maximum of $C(\hat{e})-\hat{e} C^{\prime}(\hat{e}) / \theta$ and -F. Take note that $C(\hat{e})-\hat{e} C^{\prime}(\hat{e}) / \theta_{N R}=-\mathrm{F} \cdot w_{L}(d)=C(\hat{e})-\hat{e} C^{\prime}(\hat{e}) / \theta$ implies that the expected wage is equal to the effort cost and $\theta>\theta_{N R}$. Values of $\theta$ greater than $\theta_{N R}$ increase the monitoring costs without reducing the expected wages. The optimal values of $\theta$ are then restricted to the cases where $\theta \leq \theta_{N R}$. In these cases $w_{L} *(d)=-F$ guarantees the Interim participation constraint (3) and the Limited liability constraint (4). Note that whenever the Interim participation constraint (3) is fulfilled, it will also be the Participation constraint (2).

Proposition 1b) Q.E.D.

We follow Theorem 5 in Demougin and Fluet (2001) for Proposition 1 a)

Given the results above, the cost function TC(d) minimization problem can be rewritten as:

$$
\begin{aligned}
& \underset{m(d)}{\operatorname{Min}} T C(d)=E(w(d))+M(\theta(d)-\gamma(1-d))=\hat{e} C(\hat{e}) / \theta(d)+M(\theta(d)-\gamma(1-d)), \\
& \text { s.t. } \theta(\mathrm{d})=m+\gamma(1-d) \leq \theta_{N R}
\end{aligned}
$$


$\theta_{R}(d) \in \operatorname{argmin}\left\{\frac{\hat{e} C^{\prime}(\hat{e})}{\theta(d)}+M(\theta(d)-\gamma(1-d)\}\right.$ will be an interior solution to this

problem when $\theta_{R}(d) \leq \theta_{N R} \quad$.

When $\theta_{R}(d)>\theta_{N R}$, and given that TC $(d)$ is continuously decreasing with respect

to $\theta(d) \quad$ while $\theta(d)<\theta_{R}(d)$, the optimal solution will be $\theta^{*}(d)=\theta_{N R}$.

Proposition 1 a) Q.E.D.

We follow Theorems 1 and 6 in Demougin and Fluet (2001) for Proposition 1 c).

Propositions $1 \mathrm{a}, 1 \mathrm{~b}$ and $m^{*}(1)>m^{*}(0)$ imply that if innovations are introduced, the firm will pay at least the same expected wages and will spend more on monitoring. We should then expect an increase in the firm's total cost of inducing the optimal level of effort:

$$
\Delta=T C(1)-T C(0)=\alpha /(m(1))+M(m(1))-\alpha /(\gamma+m(0))-M(m(0))>0
$$

Where $\alpha \equiv \hat{e} C^{\prime}(\hat{e})$.

Thus the net benefit of introducing an innovation, B- $\Delta$, may not always be positive. In the cases in which it is negative, it will be optimal to forbid innovations by not providing autonomy $(a=0)$. Otherwise, autonomy will be provided $(a=1)$, because it is expected a priori that innovations will take place with probability $\lambda>0$. Next, we provide a demonstration of $m^{*}(1)>m^{*}(0)$ which also guarantees that Restriction 5 is fulfilled. 
Proposition 1c (reformulated): The monitoring level is higher when there are innovations: $m^{*}(1)>m^{*}(0)>0$.

Let us to define $m_{R}(d)$ as $m_{R}(d) \equiv \theta_{R}(d)-\gamma(1-d)$

The optimal monitoring intensity $m_{R}(d)>0$ fulfils the first order condition (for $m$ ) of the minimization problem:

$\underset{m}{\operatorname{Min}} T C(d)=\frac{\alpha}{\gamma(1-d)+m}+M(m)$

F.O.C.: $-\frac{\alpha}{\left(\gamma(1-d)+m_{R}(d)\right)^{2}}+M^{\prime}\left(m_{R}(d)\right)=0$

Given the assumptions about the monitoring cost function, the second order conditions for a minimum are satisfied. The first order condition equation could have different solutions for the optimal $m$ depending on $d$. Let us define $\mathrm{n}=$ $m_{R}(d=1)-m_{R}(d=0)$ as the difference in the solution when an innovation has been introduced and when this is not the case. The first order condition implies that:

$M^{\prime}\left(m_{R}(d=0)\right)\left(\gamma+m_{R}(d=0)\right)^{2}=\alpha=M^{\prime}\left(m_{R}(d=1)\right)\left(m_{R}(d=1)\right)^{2}$.

Consequently, $\frac{\left(\gamma+m_{R}(d=1)-n\right)^{2}}{\left(m_{R}(d=1)\right)^{2}}=\frac{M^{\prime}\left(m_{R}(d=1)\right)}{M^{\prime}\left(m_{R}(d=1)-n\right)}$

Given that $\kappa^{\prime \prime}()>0$, when $\mathrm{n}=\gamma$,

$\frac{\left(\gamma+m_{R}(d=1)-n\right)^{2}}{\left(m_{R}(d=1)\right)^{2}}=1<\frac{M^{\prime}\left(m_{R}(d=1)\right)}{M^{\prime}\left(m_{R}(d=1)-n\right)}$

whereas when $\mathrm{n}=0, \frac{\left(\gamma+m_{R}(d=1)-n\right)^{2}}{\left(m_{R}(d=1)\right)^{2}}>1=\frac{M^{\prime}\left(m_{R}(d=1)\right)}{M^{\prime}\left(m_{R}(d=1)-n\right)}$.

Consequently, $0<\mathrm{n}<\gamma$. 
Given that $\theta_{R}(d) \equiv \gamma(1-d)+m_{R}(d)$, the results above imply that $\theta_{R}(0)>\theta_{R}(1)$. Thus we can find three possible situations:

Situation 1: $\theta_{N R} \geq \theta_{R}(0)>\theta_{R}(1)$. The worker obtains rents. The optimal level of monitoring conditional to the introduction of an innovation will be $m^{*}(d)=m_{R}(d)$. The expected wage of the worker $(\alpha / \theta-F)$ is higher when an innovation is introduced $(d=1)$ than otherwise $(d=0)$, therefore Restriction 5 is fulfilled with inequality. When it is possible to introduce an innovation, it is in the best interest of the worker to introduce it.

Situation 2: $\theta_{R}(0)>\theta_{R}(1)>\theta_{N R}$. The worker does not obtain rents. The optimal level of monitoring conditional to the introduction of an innovation will be $m^{*}(d)=\theta_{N R}$ $\gamma(1-d)$. By definition $\theta_{N R}>0$ and by assumption $\theta_{N R}>\gamma$, so $m *(1)-\gamma=m^{*}(0)>0$. Restriction 5 is fulfilled with equality. An innovation will be introduced whenever it is possible, although in this case the worker is indifferent about whether to introduce an innovation or not.

Situation 3: $\theta_{R}(0)>\theta_{N R} \geq \theta_{R}(1)$. The worker would not obtain rents when an innovation is not introduced $(d=0)$ and would obtain rents when an innovation is introduced $(d=1)$. The optimal level of monitoring conditional to the introduction of an innovation will be $m *(0)=m_{R}(0)=\theta_{R}(0)-\gamma>\theta_{N R}-\gamma$ and $m *(1)=\theta_{N R} \geq \theta_{R}(1)=m_{R}(1)$ . Thus $\gamma>m^{*}(1)-m^{*}(0) \geq m_{R}(1)-m_{R}(0)>0$. Restriction 5 is fulfilled with inequality when there is no innovation, and fulfilled with equality when an innovation is produced.

In all the situations Restriction 5 is fulfilled and $\gamma \geq m *(1)-m^{*}(0)>0$ and $m *(0)>0$. Proposition 1 c) Q.E.D. 


\section{Appendix 2. A model extension}

Let us assume that at Stage 0 neither the firm nor the worker knows exactly how the monitoring cost function will be at Stage 3. At Stage 0 it is common knowledge that the monitoring costs function is $M=k M(m)$, where $k$ is a random variable with a maximum

and minimum value, $\bar{k} \geq k \geq \underline{k}>0$, and a probability density function $K(k)$. The task decision (Stage 2) is irrevocable, since it is highly costly to change once one has been adopted. The value of $k$ is realized in Stage 3, before the monitoring level is implemented. The value $k$ is observed by all the parties and is contractible.

Proposition 1.A: An optimal contract to implement a level of effort $\hat{e}$ is determined by the following conditions:

a) The optimal information level for performance is:

$$
\begin{aligned}
& \theta^{*}(d, k)=\operatorname{Min}\left\{\theta_{R}(d, k), \theta_{N R}\right\} \quad, \text { where } \\
& \theta_{R}(d, k) \in \arg \min \left\{\frac{\hat{e} C^{\prime}(\hat{e})}{\theta(d, k)}+M(\theta(d, k)-\gamma(1-d)\}\right. \\
& \theta_{N R}=\frac{\hat{e} C^{\prime}(\hat{e})}{C(\hat{e})+F},
\end{aligned}
$$

where $m^{*}(d, k) \equiv \theta^{*}(d, k)-\gamma(1-d)>0$ then $\gamma \geq m^{*}(1, k)-m^{*}(0, k)>0$.

b) The optimal wages contingent on the monitoring signal $I=\{H, L\}$ are:

$$
\begin{aligned}
& w_{L}^{*}(d, k)=-F \\
& w_{H} *(d, k)=C^{\prime}(\hat{e}) / P^{* \prime}(\hat{e})-\mathrm{F}
\end{aligned}
$$

Where, $P^{*}(\hat{e}, k)=P\left(H / \theta^{*}(d, k)\right)$. 
c) The optimal level of autonomy is:

$$
a^{*}= \begin{cases}1 & \text { if } B-\Delta^{*} \geq 0 \\ 0 & \text { otherwise }\end{cases}
$$

Where $\Delta^{*}=\int_{k}^{\bar{k}}(T C *(1, k)-T C *(0, k)) K(k) d k$

The model in the main text can be considered as being a particular case $(K(k=1)=1)$ for this general setting. The main difference is that the optimal level of monitoring (and consequently wages) will be conditional to the marginal monitoring costs function $k$, by following in each of the cases all the conditions described in Proposition 1a and $1 \mathrm{~b}$. By replacing these values in the function TC, we can define $T C^{*}(1, k)$ and $T C *(0, k)$. Proposition 1c follows as stated, with the difference that:

$$
\Delta^{*}=\int_{\underline{k}}^{\bar{k}}(T C *(1, k)-T C *(0, k)) K(k) d k
$$

The decision on autonomy is now based on expectations about the level of monitoring. Those firms that provide autonomy will expect higher levels of monitoring (Hypothesis 1). The optimal information level, $\theta^{*}(d, k)$, on accordance with Propositions $1 \mathrm{~A}$ a and b will have the following properties:

$$
\partial \theta^{*}(d, k) / \partial k<0 \text { for } k<k_{\mathrm{NR}}(d) \text { where } \theta *(d, k)=\theta_{\mathrm{NR}} \text {. }
$$

$\theta^{*}(d, k)=\theta_{\mathrm{NR}}$ for $k \geq k_{\mathrm{NR}}(d)$.

Given a certain level of autonomy, when $k_{N R}>k \geq \underline{k}$, the optimal information level will be $\theta_{\mathrm{NR}}$ and the workers will not obtain rents. When $\bar{k} \geq k \geq k_{N R}$, the optimal information level (monitoring) will be lower and the workers will obtain rents (Hypothesis 2). 